\title{
CAMA
}

Centre for Applied Macroeconomic Analysis

\section{Speculative Bubbles or Market Fundamentals? An Investigation of US Regional Housing Markets}

\section{CAMA Working Paper 46/2016 July 2016}

\section{Shuping Shi}

Macquarie University and

Centre for Applied Macroeconomic Analysis, ANU

\section{Abstract}

This paper investigates the existence of speculative bubbles in the US national and in 23 regional housing markets over three decades (1978-2012). A new method for detecting exuberance in housing markets is proposed. By taking changes in the macroeconomic conditions (such as interest rate, per-capita income, employment, and population growth) into consideration, the new method provides a better control for housing market fundamentals and thereby it is expected to significantly reduce the chance of false positive identification. Compared with the method of Phillips, Shi and Yu (2015a,b), the new approach finds a dramatic reduction in the number of speculative housing markets and shorter bubble episodes in the US. It locates only one bubble episode in the earlyto-mid 2000s over the whole sample period in the national housing market. At the regional level, it identifies three periods of speculation: late 1980s, early-to-mid 2000s, and the post-crisis period in 2011-2012. The early-to-mid 2000s bubble episode is the most severe one involving nine major metropolitan statistical areas. 


\section{Keywords}

Speculative bubbles, Housing market, Fundamentals, Macroeconomic conditions, Regional, Explosive

\section{JEL Classification}

C12, C51, R31, E31

\section{Address for correspondence:}

(E) cama.admin@anu.edu.au

\section{ISSN 2206-0332}

The Centre for Applied Macroeconomic Analysis in the Crawford School of Public Policy has been established to build strong links between professional macroeconomists. It provides a forum for quality macroeconomic research and discussion of policy issues between academia, government and the private sector.

The Crawford School of Public Policy is the Australian National University's public policy school, serving and influencing Australia, Asia and the Pacific through advanced policy research, graduate and executive education, and policy impact. 


\title{
Speculative Bubbles or Market Fundamentals? An Investigation of US Regional Housing Markets*
}

\author{
Shuping Shi \\ Macquarie University and CAMA
}

June 7, 2016

\begin{abstract}
This paper investigates the existence of speculative bubbles in the US national and in 23 regional housing markets over three decades (1978-2012). A new method for detecting exuberance in housing markets is proposed. By taking changes in the macroeconomic conditions (such as interest rate, per-capita income, employment, and population growth) into consideration, the new method provides a better control for housing market fundamentals and thereby it is expected to significantly reduce the chance of false positive identification. Compared with the method of Phillips, Shi and Yu (2015a,b), the new approach finds a dramatic reduction in the number of speculative housing markets and shorter bubble episodes in the US. It locates only one bubble episode in the early-to-mid 2000s over the whole sample period in the national housing market. At the regional level, it identifies three periods of speculation: late 1980s, early-to-mid 2000s, and the post-crisis period in 2011-2012. The early-to-mid 2000s bubble episode is the most severe one involving nine major metropolitan statistical areas.

Keywords: Speculative bubbles, Housing market, Fundamentals, Macroeconomic conditions, Regional, Explosive
\end{abstract}

JEL classification: C12, C51, R31, E31

${ }^{*}$ Shuping Shi, Department of Economics, Macquarie University; Email: shuping.shi@mq.edu.au. 
"Although the house price bubble appears obvious in retrospect-all bubbles appear obvious in retrospect-in its earlier stages, economists differed considerably about whether the increase in house prices was sustainable; or, if it was a bubble, whether the bubble was national or confined to a few local markets." Bernanke (2010)

\section{Introduction}

Following the 2008 subprime mortgage crisis there has been widespread recognition of the harm that speculative housing bubbles can inflict on the aggregate economies. The bursting of housing bubbles or a severe decline in house prices could lead to an extensive reduction in household consumption [Case et al. (2005), Skinner (1996), Case (1992)] and may result in more foreclosures and unanticipated losses for lenders [see Case et al. (2000) among others], exacerbating the development of a negative economic shock and leading to a greater general economic decline. ${ }^{1}$

In the aftermath of the crisis, policy-makers have been urged to deepen their understanding about how to combat speculative bubbles. ${ }^{2}$ One major challenge to policy-making is identifying the presence of speculative behaviour in housing markets as quoted above. Measures commonly used to gauge deviations from fundamentals are the affordability ratios, including price-to-rent ratio and price-to-income ratio. These measures also form the basis for several popular bubble detection techniques. These include the recursive window bubble tests of Phillips et al. (2011, 2015a,b), the CUSUM test of Homm and Breitung (2012), and the Markov-switching bubble test [Hall et al. (1999), Shi (2013), Shi and Song (2016)].

Those techniques, especially the recursive window bubble test, have attracted attention from policy-makers and fiscal regulators. For example, the Federal Reserve Bank of Dallas is now publishing a quarterly exuberance indicator, calculated from the bubble test of Phillips, et al. (2015a,b, PSY hereafter), for 23 national housing markets. ${ }^{3}$ The common ground for these approaches is the following two equations. Let $p_{t}$ be the $\log$ real price of housing and $r_{t}$ be the log real housing rent. The price-to-rent ratio consists of a market fundamental $\left(F_{t}\right)$ and a bubble component $\left(B_{t}\right)$ such that

$$
p_{t}-r_{t}=F_{t}+B_{t}
$$

\footnotetext{
${ }^{1}$ See McCarthy and Peach (2004)) for a detailed review.

${ }^{2}$ By the former Federal Reserve Board vice chairman Donald Kohn (March 24, 2010).

${ }^{3}$ http://www.dallasfed.org/institute/houseprice/
} 
The bubble component $B_{t}$ satisfies the submartingale property (Diba and Grossman, 1988)

$$
E_{t}\left(B_{t+1}\right)=\frac{1}{\rho} B_{t} \operatorname{with} \frac{1}{\rho}>1 .
$$

In the presence of speculative bubbles, the price-to-rent ratio defined as the sum of the market fundamental and the bubble components follows an explosive process. The key task of these techniques is to detect the existence of explosive dynamics in asset prices or the price-to-rent ratio. It is a convention in the empirical literature that bubble detection techniques are applied separately to the $\log$ real housing price index and the log real rent index, or to the price-to-rent ratio. ${ }^{4}{ }^{5}$ The rent index serves as a proxy for the housing market fundamental.

Despite the econometric competency of these approaches, an inference of bubble existences based simply on affordability measures can be misleading. This is because the important impact of the aggregate economy on housing markets, such as changes in interest rates influencing home ownership affordability and economic and population growth reflecting the demand for housing is ignored.

This paper proposes a new bubble detection method for the housing market, with an emphasis on distinguishing between a rapid rise in home prices induced by changes in fundamentals and a housing price bubble. Unlike existing bubble detection techniques, the new method explores information beyond housing markets and takes the impact of the aggregate economy conditions into consideration. As in Campbell et al. (2009), we assume that macroeconomic factors affect housing market fundamentals through rent and interest rates. Thereby, variables reflecting the aggregate economic conditions such as interest rates, per capita GDP, population and employment growth rates are included in a VAR model to forecast future streams of rent and interest rates. These two streams are subsequently used to obtain estimates of the fundamental. The recursive bubble detection method of PSY is then applied to the residual component to identify the start and end dates of bubble episodes. This is in sharp contrast to the existing bubble detection techniques where the methods are applied directly to the price-to-rent ratio. In other words, with the existing methods, the only proxy used for capturing housing market fundamentals is the historical and current rent.

\footnotetext{
${ }^{4}$ The price-to-rent ratio is often replaced by the price-to-income ratio when the rent index is not available.

${ }^{5}$ See, for example, Caspi (2015), Engsted et al. (2014), Pavlidis et al. (2015), Kishor and Morley (2015), and Greenaway-McGrevy and Phillips (2015).
} 
There are papers in the literature that attempt to control for the impact of real interest rates on housing markets fundamentals. Kivedal (2013) incorporates interest rate dynamics into the calculation of imputed rents and uses imputed rates for the analysis of bubble existence. The imputed rates are, however, calculated in an ad hoc way using a formula of $R_{t} /\left(1+i_{t}\right)$, where $R_{t}$ is the actual rental price and $i_{t}$ is the 10-year government bond rate. Caspi (2015) suggests that, like the rent index, one should also conduct explosiveness tests on the real interest rate. Inference of bubble existence is affirmative if there is an explosive dynamic in the log price-to-rent ratio but not in either the log real rent or log real interest rate. Unfortunately, this extension is immaterial as in reality we do not observe explosive rates of interest, not withstanding that interest rates become explosive simultaneously with the price-to-rent ratio. It is more often the case that a prolonged period of low interest rates stimulates housing demand and hence leads to a rapid increase in housing prices. Therefore, the real interest rate is not appropriate as a direct proxy for housing fundamentals.

The new approach is a novel development with wide-ranging policy implications. We apply the new method to the US national and to 23 metropolitan statistical areas (MSA) from 1978 to 2012. As quoted above, the question of whether the bubble was national or confined to a few local markets is of critical importance to policy-making. By controlling for the impact of macroeconomic factors on housing markets, the new method leads to distinct conclusions of bubble existence from the standard PSY method. With the new method, we observe significant reductions in the numbers of MSAs experiencing speculative housing bubbles and shorter speculative episodes. In particular, the number of speculative MSA housing markets reduces from 21 (obtained from the standard PSY method) to three (with the new method) in 2003. At the national level, the number of bubble episodes declines from two to one. The new method suggests a bubble origination date of 2001:H1 ${ }^{6}$ as opposed to 1998:H2 obtained from the standard PSY test. The estimated bubble origination date when using the new method is much later than that from the original PSY test based on the log price-to-rent ratio. This suggests that the explosive dynamics in the price-to-rent ratio between 1998:H2 and 2000:H2 are likely due to changes in the market fundamentals.

The rest of the paper is organized as follows. Section 2 introduces the market fundamental and bubble decomposition method. Section 3 describes the data used in this paper and presents the

\footnotetext{
${ }^{6} \mathrm{H} 1$ and $\mathrm{H} 2$ denote the first and second half of the year respectively.
} 
estimated bubble components for the 23 metropolitan statistical areas and the nation. In Section 4, the PSY procedure for bubble detection is introduced and the bubble detection results for all of the markets are illustrated. Section 5 concludes.

\section{House Prices and Fundamentals}

Consider the one-period gross return to housing

$$
V_{t+1}=\frac{P_{t+1}+R_{t+1}}{P_{t}}
$$

where $P$ is the real price of housing and $R$ is the real housing rent. The first order Taylor series expansion gives the following expression of the log housing price

$$
p_{t}=\kappa+\rho p_{t+1}+(1-\rho) r_{t+1}-v_{t+1} .
$$

where $v_{t+1}=\log V_{t+1}, p_{t+1}=\log P_{t+1}, r_{t+1}=\log R_{t+1}, \rho=e^{\bar{p}} /\left(e^{\bar{p}}+e^{\bar{r}}\right)$, and $\kappa=-\log (\rho)+$ $(1-\rho)(\bar{p}-\bar{r})$ with $\bar{p}$ and $\bar{r}$ being the sample means of $p_{t}$ and $r_{t}$. By iterating (2) forward, we can obtain

$$
\begin{aligned}
p_{t} & =\frac{\kappa}{1-\rho}+(1-\rho) \sum_{j=0}^{\infty} \rho^{j} r_{t+1+j}-\sum_{j=0}^{\infty} \rho^{j} v_{t+1+j}+B_{t} \\
B_{t} & \equiv \lim _{j \rightarrow \infty} \rho^{j} p_{t+j},
\end{aligned}
$$

The bubble component $B_{t}$ satisfies equation (1).

It follows immediately from (3) that

$$
p_{t}-r_{t}=F_{t}+B_{t} \text { with } F_{t} \equiv \frac{\kappa}{1-\rho}+\sum_{k=0}^{\infty} \rho^{k}\left(\Delta r_{t+1+k}-v_{t+1+k}\right) .
$$

Furthermore, we assume the log gross return to housing to equal the summation of a constant risk premium $(\varphi)$, a risk-free interest rate $\left(i_{t+1}\right)$ and a zero mean residual $\left(\varepsilon_{t+1}\right)^{7}$ such that

$$
v_{t+1}=\varphi+i_{t+1}+\varepsilon_{t+1} .
$$

Therefore, the future stream of gross return to housing $\left\{\hat{v}_{t+j}\right\}_{j=1}^{\infty}$ can be estimated as

$$
\hat{v}_{t+j}=\hat{\varphi}+\hat{\imath}_{t+j},
$$

\footnotetext{
${ }^{7}$ This differs from the literature [Campbell et al. (2009) and Sun and Tsang (2013)] where the log gross return to housing is assumed to be the sum of the real risk-free rate and a time-varying risk premium, i.e. $v_{t+1}=\varphi_{t+1}+i_{t+1}$.
} 
where $\hat{\varphi}$ is the OLS estimate of $\varphi$ and $\hat{\imath}_{t+j}$ is the expected future interest rate. The market fundamental component $F_{t}$ is then estimated as

$$
\hat{F}_{t}=\frac{\tilde{\kappa}-\hat{\varphi}}{1-\tilde{\rho}}+\left[\sum_{k=0}^{\infty} \tilde{\rho}^{k} \Delta \hat{r}_{t+1+k}-\sum_{k=0}^{\infty} \tilde{\rho}^{k} \hat{\imath}_{t+1+k}\right]
$$

where $\tilde{\kappa}$ and $\tilde{\rho}$ are calibrated model parameters based on historical data, and $\left\{\Delta \hat{r}_{t+j}\right\}_{j=1}^{\infty}$ is the expected future rent growth rates. The market fundamental consists of two major components: the present value of the future real risk-free interest rates and rent growths. To estimate the market fundamental component, we need to forecast future streams of real interest rates and rent growth rates.

\subsection{The VAR system}

The forecasting is based on VAR models. We consider a separate second-order VAR model for each of the 24 (the US national and $23 \mathrm{MSA}$ ) housing markets in our sample. Let $\Delta Y, \Delta L$ and $\Delta N$ be the real per-capita income growth, employment growth, and population growth respectively. We label national level variables with a superscript US. For the US national market, the VAR system contains five variables, i.e. $\left\{\Delta r_{t}^{U S}, i_{t}, \Delta Y_{t}^{U S}, \Delta L_{t}^{U S}, \Delta N_{t}^{U S}\right\}$. For the metropolitan areas, the VAR system has nine variables: the five national variables and four local variables $\left\{\Delta r_{t}, \Delta Y_{t}, \Delta L_{t}, \Delta N_{t}\right\}$. Each of these variables depends on the first and second lags of the real rate $\left(i_{t-1}\right.$ and $\left.i_{t-2}\right)$ and rent growth $\left(\Delta r_{t-1}\right.$ and $\left.\Delta r_{t-2}\right)$ and the second and fourth lag of income growth $\left(\Delta Y_{t-2}\right.$ and $\left.\Delta Y_{t-4}\right)$, employment growth $\left(\Delta L_{t-2}\right.$ and $\left.\Delta L_{t-4}\right)$, and population growth $\left(\Delta N_{t-2}\right.$ and $\left.\Delta N_{t-4}\right){ }^{8}$ The national level variables only depend on the lags of national variables; the local variables depend on the lags of local variables plus the interest rate. For instance, the forecasting equation for the real interest rate is

$$
\begin{aligned}
i_{t} & =\delta_{0}+\delta_{1} \Delta r_{t-1}^{U S}+\delta_{2} i_{t-1}+\delta_{3} \Delta Y_{t-2}^{U S}+\delta_{4} \Delta L_{t-2}^{U S}+\delta_{5} \Delta N_{t-2}^{U S} \\
& +\delta_{6} \Delta r_{t-2}^{U S}+\delta_{7} i_{t-2}+\delta_{8} \Delta Y_{t-4}^{U S}+\delta_{9} \Delta L_{t-4}^{U S}+\delta_{10} \Delta N_{t-4}^{U S}+\varepsilon_{1 t},
\end{aligned}
$$

\footnotetext{
${ }^{8}$ We use the second lag, rather than the first lag, of the macroeconomic condition variables. This is because these data are observed at an annual frequency and are assumed to be constant throughout the year. Thus, once these variables are converted to semi-annual frequency, the second lag is used in the regression to ensure that macroeconomic conditions data from year $t-1$ are always used to forecast variables in year $t$.
} 
which only depends on national level variables. The right-hand side variables for the equations of $\left\{\Delta r_{t}^{U S}, \Delta Y_{t}^{U S}, \Delta L_{t}^{U S}, \Delta N_{t}^{U S}\right\}$ are the same as those for equation (5). The dynamics of local rent growth is

$$
\begin{gathered}
\Delta r_{t}=\gamma_{0}+\gamma_{1} \Delta r_{t-1}+\gamma_{2} i_{t-1}+\gamma_{3} \Delta Y_{t-2}+\gamma_{4} \Delta L_{t-2}+\gamma_{5} \Delta N_{t-2} \\
\gamma_{6} \Delta r_{t-2}+\gamma_{7} i_{t-2}+\gamma_{8} \Delta Y_{t-4}+\gamma_{9} \Delta L_{t-4}+\gamma_{10} \Delta N_{t-4}+\varepsilon_{2 t}
\end{gathered}
$$

Note that all variables used in forecasting rent growth are measured at the local market level, except the real interest rate. The equations for $\left\{\Delta Y_{t}, \Delta L_{t}, \Delta N_{t}\right\}$ have the same independent variable as the above equation. We estimate each VAR by the maximum likelihood method. ${ }^{9}$

\subsection{Calculating expected components}

The companion form of the VAR systems is

$$
Z_{t}=A_{0}+A_{1} Z_{t-1}+\varepsilon_{t}
$$

For the metropolitan system, $Z_{t}$ contains 30 variables including nine national and local variables at period $t$, i.e. $\Delta r_{t}^{U S}, i_{t}, \Delta Y_{t}^{U S}, \Delta L_{t}^{U S}, \Delta N_{t}^{U S}, \Delta r_{t}, \Delta Y_{t}, \Delta L_{t}, \Delta N_{t}$, the same nine variables at period $t-1$, the national and local macroeconomic variables at period $t-2$, i.e. $\Delta Y_{t-2}^{U S}$, $\Delta L_{t-2}^{U S}, \Delta N_{t-2}^{U S}, \Delta Y_{t-2}, \Delta L_{t-2}, \Delta N_{t-2}$, and period $t-3$. For the national VAR system, $Z_{t}$ includes only the 16 national variables in the metropolitan $Z_{t}$. The matrix $A$ is called the companion matrix of the VAR.

The conditional forecasting of $Z_{t}$ is

$$
E\left(Z_{t+s} \mid H_{t}\right)=\left(I-A_{1}^{s}\right)\left(I-A_{1}\right)^{-1} A_{0}+A_{1}^{s} Z_{t},
$$

where $H_{t}$ is the limited information set containing current and lagged value of $i_{t}, r_{t}$, and the macroeconomic variables. The optimal forecasts of the future real interest rate and rent growth at period $t+s$ are the rows in $\left(I-A_{1}^{s}\right)\left(I-A_{1}\right)^{-1} A_{0}$ and $A_{1}^{s} Z_{t}$ corresponding to the dependent variable $i_{t}$ and $\Delta r_{t}$. Therefore, the optimal forecast of the market fundamental component $F_{t}$ is

$$
E\left(F_{t} \mid H_{t}\right)=\frac{\kappa-\varphi}{1-\rho}+\left(\mathbf{h}_{1}^{\prime}-\mathbf{h}_{2}^{\prime}\right)(1-\rho)^{-1}\left(I-\rho A_{1}\right)^{-1} A_{0}+\left(\mathbf{h}_{1}^{\prime}-\mathbf{h}_{2}^{\prime}\right) A_{1}\left(I-\rho A_{1}\right)^{-1} \mathbf{Z}_{t},
$$

\footnotetext{
${ }^{9}$ Note that Campbell et al. (2009) employs a first order VAR model with macroeconomic variables while Sun and Tsang (2013) estimates a VAR(2) model without macroeconomic variables. Both papers include the time-varying risk premium variable (defined in footnote 7) in the VAR models.
} 
where $\mathbf{h}_{1}$ and $\mathbf{h}_{2}$ are column vectors with 30 elements for the metropolitan system (16 elements for the national system), all of which are zeros except for the $6^{\text {th }}$ element in $\mathbf{h}_{1}^{\prime}$ and the $2^{\text {nd }}$ element of $\mathbf{h}_{2}^{\prime}$ for the metropolitan system (the $1^{\text {st }}$ element in $\mathbf{h}_{1}^{\prime}$ and the $2^{\text {nd }}$ element of $\mathbf{h}_{2}^{\prime}$ for the national system), which are unity. In the calculation of $\hat{F}_{t}$, we replace $\varphi, A_{0}$ and $A_{1}$ with their estimated values and $\kappa$ and $\rho$ with their calibrated values. The bubble/residual component is

$$
\hat{B}_{t}=p_{t}-r_{t}-\hat{F}_{t}
$$

\section{Data Description}

The estimation of the market fundamental component requires three sets of data series: $(i)$ house price, rent, CPI excluding shelter; (ii) 10-year treasury yield and the median 10-year inflation expectations; (iii) per-capita income, employment, and population. All data are collected or converted to a semi-annual frequency for 23 separate metropolitan areas and the nation for the sample period running from 1978:H1 to 2012:H2, containing 69 observations. We convert higher frequency data series (quarterly or monthly) to a semi-annual frequency by averaging.

\subsection{House price and rent}

House price indices, proxied by the repeat-transaction house price indices, are obtained from the Federal Housing Finance Agency. These data measure the movement of single-family house prices. It is a weighted repeat-sales index, representing average price changes in repeat sales or refinancing on the sample properties. The data are converted from quarterly to semi-annual frequency by averaging (non-seasonally adjusted, base year 1995:Q1 =100). The rent index is proxied by the rent of the primary residence, which is a component of the consumer price index (all urban consumers). It is gathered from Bureau of Labor Statistics (BLS, non-seasonally adjusted, base year 1982-84 = 100). The BLS calculates the rents of renter-occupied accommodation by directly asking for their monthly rent.

The bubble component equals the difference between the price-to-rent ratio and the forecasted fundamental component, ${ }^{10}(7)$. Importantly, this calculation requires the actual rent and house

\footnotetext{
${ }^{10}$ The forecasting of the fundamental component is independent of the price-to-rent ratio - the price-to-rent ratio does not enter the VAR system.
} 
values, instead of indices. As in Campbell et al. (2009) and Davis et al. (2008), we calculate owneroccupied house prices and rent values in 2000 for the US and each metropolitan statistical area and extrapolate with the corresponding index.

The 2000 Decennial Census of Housing (DCH) survey provides one percent of household-level data. ${ }^{11}$ For the US, we regress $\log$ gross rents of renters (contract rent plus costs for utilities) on Metropolitan Statistical Areas (MSA) of residence, state of residence, the estimated age of the structure, and number of bedrooms. For each MSA, we regress log gross rent of renters on the estimated age of the structure and number of bedrooms. Using the coefficient estimates from the hedonic regressions, we predict gross rents for each owner-occupied property in the sample and subtract the reported utilities costs of owner-occupiers to compute net rent. The annual utility expenditure of owner-occupiers includes the annual cost of home heating fuel, gas, electricity, and water.

Figure 1 displays the calculated 2000 average house price and rental values for the US and all the metropolitan areas. The average house price and rent in the year 2000 for the nation were $\$ 212,147$ and $\$ 6,887$ respectively. ${ }^{12}$ In terms of average housing prices, in 2000 San Francisco was the most expensive city with an average price of $\$ 575,715$, followed by Honolulu, Boston and New York (with average housing prices of $\$ 390,830, \$ 328,110$ and $\$ 315,333$ respectively). As for rent, San Francisco and Honolulu remain number one and two (with average monthly net rent exceeding $\$ 10,000$ ), followed by Seattle, San Diego and Denver (with net rent above $\$ 9,000$ per month). Interestingly, although by house price it is ranked number four, the average monthly net rent in New York is lower than the national average at only $\$ 4,844$.

We extrapolate the calculated average house and rent prices in 2000 with the price and rent indices (national and each local-areas indices). To obtain the real house prices and real rents $\left(P_{t}\right.$ and $R_{t}$ ), we deflate the nominal series using the national CPI excluding shelter, downloaded from federal reserve economic data. The CPI less shelter series is disaggregated to remove the influence from accommodation expenses. The annualized real growth rate of rent is calculated as

\footnotetext{
${ }^{11}$ Downloaded from https://usa.ipums.org/usa/.

${ }^{12}$ The house value is below that of Davis et al. (2008): $\$ 165,556$, while the rent value is slightly below that of Davis et al. (2008): \$7,704. Note that Davis et al. (2008) uses the five Decennial Census of Housing (DCH) surveys, 1960-2000 every 10 years, to develop the benchmark estimates, whereas we use only the survey data from 2000 as in Campbell et al. (2009) and Sun and Tsang (2013). The benchmark price and rent values in 2000 are not reported in Campbell et al. (2009) and Sun and Tsang (2013).
} 
$\Delta r_{t}=2\left(\log R_{t}-\log R_{t-1}\right)$. The annualized real return to housing is obtained using the formula $v_{t}=2\left(P_{t}+R_{t}-P_{t-1}\right) / P_{t-2} \cdot{ }^{13}$

Figure 2 presents the log price-to-rent ratio of the 23 metropolitan areas in four panels: MidWest (a), Northeast (b), South (c), and West (d). One can see that the ratio ranges roughly between 2.5 to 4.5. The highest price-to-rent ratio is due to New York. The first obvious rise in the $\log$ price-to-rent ratio happens towards the end of the 1980s. This is particularly obvious in some of the Northeast and West MSAs such as New York, Boston, Honolulu, Los Angeles, San Diego, San Francisco, and Seattle. There is another dramatic increase in the ratio of almost all metropolitan areas around 2004-2006, right before before the subprime mortgage crisis. Both episodes are also observed at the national log price-to-rent ratio displayed in Figure 3(a). The question of interest here is whether those increases are due to speculative bubble behaviour or to changes in housing market fundamentals.

\subsection{Real interest rate and macroeconomic variables}

Real interest rate $\left(i_{t}\right)$ is an estimate of the ex-ante real expected yield on a 10-year US treasury bond. It is defined as the nominal 10-year treasury yield less the median reading of 10-year inflation expectations from professional forecasters. The 10-year treasury yield is also known as a constant maturity treasury rate. This yield is interpolated by the treasury from the daily yield curve to its time to maturity. The 10-year yield values are read at the fixed maturity of 10 years. The data are obtained from Federal Reserve Economic Data(averaged daily data and non-seasonally adjusted). The professional forecast of 10-year inflation expectations is downloaded from the Federal Reserve Bank of Philadelphia. ${ }^{14}$ The housing premia $\varphi$ is calculated as the average of the difference between $v_{t}$ and $i_{t}$.

The macroeconomic variables, including per-capita income, employment and population, are collected from the Bureau of Economic Analysis at an annual frequency. They are converted to a semi-annual frequency by assuming a constant figure throughout the year. The per-capita income is calculated as the total nominal personal income of the residents of an area divided by the population of the area. The annual population growth rates of those macroeconomic variables are calculated

\footnotetext{
${ }^{13}$ Note that this equals approximately $2\left[\log \left(P_{t}+R_{t}\right)-\log \left(P_{t-1}\right)\right]$.

${ }^{14}$ The primary source of the data is from the Blue Chip Economic Indicator forecast for the 1975:H1 to 1990:H2 period, and from the Livingston survey from 1991:H1 to the end of the sample.
} 
as $\log \left(X_{t}\right)-\log \left(X_{t-2}\right)$.

Figure 3(a) displays the log price-to-rent ratio, annualized real growth rate of rent, and the real interest rate of the nation. The annualized growth rates of real per capita income, employment and population of the nation are in Figure 3(b). It is obvious that corresponding to the rise in the $\log$ price-to-rent ratio in the late 1980s, there is a dramatic increase in the population growth rate and a significant decline in the employment and real per capita income growth rates. Meanwhile, we observe a large drop in the real interest rate before and around 1987. In contrast, there is no obvious pattern of changes in the real interest rate or macroeconomic variables during 2004-2006.

\subsection{Estimation results and the bubble components}

In Figure 4 (a)-(e), we plot both the actual and the fitted series of real rent growth, real interest rate, real per capita GDP growth rate, employment growth rate, and population growth rate. Remember that the real per capita GDP growth, employment growth, and population growth rates are included in the VAR system to assist forecasting of the real rent growth and real interest rate. As can be seen from Figure 4, the VAR model fits the historical data series of those variables very well, particularly the real interest rate. ${ }^{15}$ Panel (f) displays the national log price-to-rent ratio (left axis) and the calculated bubble component of the data series (right axis). The dynamics of the bubble (residual) component closely follows the log price-to-rent ratio.

Next, we estimate the VAR model for all 23 metropolitan areas and obtain the corresponding bubble components. Figure 5 plots the residual components of all MSAs, separating them by regions. It is immediately noticeable that there is much more heterogeneity among the regional bubble components than among the log price-to-rent ratios. While the upward surge in 2004-06 in the log price-to-rent ratio remains visible in the bubble components of many metropolitan areas, the rising trend in the log price-to-rent ratio in the late 1980s becomes less obvious in the bubble components of most northeast metropolitan areas. In the next section, we introduce the explosive date-stamping strategy of Phillips et al. (2015a) and apply it to the calculated bubble components.

\footnotetext{
${ }^{15}$ We have also estimated first order VAR models for all markets. The second order VAR model fits the data series much better than the first order VAR model.
} 


\section{Speculative Bubble Behaviours in the Housing Markets}

\subsection{The PSY procedure for explosiveness}

The interest of the testing algorithm is whether a particular observation comes from an explosive process $\left(H_{A}\right)$ or a normal martingale behaviour $\left(H_{0}\right)$. The testing algorithm is based on a righttailed unit root test proposed by Phillips et al. (2014). The martingale null is specified as

$$
H_{0}: y_{t}=k T^{-\eta}+y_{t-1}+\varepsilon_{t}, \text { with constant } k \text { and } \eta>1 / 2,
$$

where $y_{t}$ is data series of interest (either the log price-to-rent ratio or the bubble component) at period $t, \varepsilon_{t}$ is the error term, and $T$ is the total sample size. The alternative is a mildly explosive process, namely

$$
H_{A}: y_{t}=\delta_{T} y_{t-1}+\varepsilon_{t},
$$

where $\delta_{T}=1+c T^{-\alpha}$ with $c>0$ and $\alpha \in(0,1)$. The fitted regression model is

$$
\Delta y_{t}=\alpha+\beta y_{t-1}+\sum_{i=1}^{K} \gamma_{i} \Delta y_{t-i}+\varepsilon_{t},
$$

which includes an intercept but no time trend and $K$ is the lag order.

Let $r_{0}$ be the (fractional) minimum window size required to initiate a regression. Using the PSY dating algorithm, one can draw an inference of explosiveness for each observation between $r_{0}$ and 1 (corresponding to the last observation of the sample $T$ ). Suppose $r$ is the observation of interest, the algorithm calculates the augmented Dickey-Fuller (ADF) statistic repeatedly on a sequence of backward expanding samples. The ending points of all samples $r_{2}$ are fixed on $r$ and the starting point of the samples $r_{1}$ varies from 0 (the first observation) to $r-r_{0}$. The corresponding ADF statistic sequence is denoted by $\left\{A D F_{r_{2}}^{r_{1}}\right\}_{r_{2}=r}^{r_{1} \in\left[0, r-r_{0}\right]}$. Inference of explosiveness for observation $r$ is based on the supremum of the ADF sequence, denoted by $B S A D F_{r}$ and defined as

$$
B S A D F_{r}=\sup \left\{A D F_{r_{2}}^{r_{1}}: r_{2}=r \text { and } r_{1} \in\left[0, r-r_{0}\right]\right\} .
$$

Under the null hypothesis, the test statistic $B S A D F_{r}$ follows an asymptotic distribution of

$$
\sup _{\substack{r_{1} \in\left[0_{2}, r_{2}-r_{0}\right] \\ r_{2}=r}}\left\{\frac{\frac{1}{2} r_{w}\left[W\left(r_{2}\right)^{2}-W\left(r_{1}\right)^{2}-r_{w}\right]-\int_{r_{1}}^{r_{2}} W(s) d s\left[W\left(r_{2}\right)-W\left(r_{1}\right)\right]}{r_{w}^{1 / 2}\left\{r_{w} \int_{r_{1}}^{r_{2}} W(s)^{2} d s-\left[\int_{r_{1}}^{r_{2}} W(s) d s\right]^{2}\right\}^{1 / 2}}\right\},
$$


where $r_{w}=r_{2}-r_{1}$. Let $s c v^{\beta_{T}}$ as the $100\left(1-\beta_{T}\right) \%$ quantile of the asymptotic distribution and hence the $100\left(1-\beta_{T}\right) \%$ critical value of the test statistic. The origination (termination) of an explosive episode is defined as the first chronological observation whose test statistic exceeds (goes below) its corresponding critical value. Phillips et al. (2015b) prove that under a mild regularity condition, the test strategy can consistently estimate the origination and termination dates of explosive episodes in both single and multiple explosiveness scenarios.

\subsection{Empirical results}

The PSY procedure is applied separately to both the original log price-to-rent ratios and the estimated bubble components. While both approaches control for the impact of rent growth, the procedure based on the bubble component controls for broader market fundamentals such as the real interest rate and changes in other macroeconomic conditions (population, real GDP per capita, and employment). One would conclude that there is speculative bubble behaviour in the housing market if explosive dynamics are detected in the log price-to-rent ratio for the original procedure and in the bubble component for the newly proposed method.

The lag order is selected by BIC with a maximum lag order of six. The minimum window size is set according to the rule suggested by PSY, i.e. $r_{0}=0.01+1.8 / \sqrt{T}$., containing 15 observations. Therefore, the test statistics start from 1985:H1 for tests based on the log price-to-rent ratios and from 1987:H1 for tests based on the bubble components (four observations were consumed in the VAR estimation). The finite sample critical value sequences are obtained by Monte Carlo simulation with 5,000 replications.

Figure 6 plots the BSADF statistics against the $95 \%$ critical value sequences for the national housing market - panel (a) for the log price-to-rent ratio and panel (b) for the bubble component. The PSY procedure based on the log price-to-rent ratio suggests the existence of two bubble episodes: one in 1989:H2 and one occurring right before the subprime mortgage crisis. When applying the test to the bubble component, the episode of 1989 disappears, suggesting that the explosive dynamic in the log price-to-rent ratio is due to changes in the broader market fundamental. For the second episode, the identified bubble period based on the bubble component is visibly shorter than that from the log price-to-rent ratio. The former suggests a period running from 2001:H1 to 2007:H1, whereas the starting point indicated by the latter is 1998:H2, which is 2.5 years earlier, 
and the termination date is two quarters behind (2007:H2).

Next, we compare the numbers of MSA housing markets that are found to have speculative behaviours using the PSY procedure based on the log price-to-rent ratio and the bubble component. Figure 7 plots both numbers at each time period for the whole sample. First, as expected, for all periods the latter, which controls for the broader market fundamental, finds a significantly less number of speculative markets than the former. For example, the test procedure based on the bubble component detects two explosive housing markets in 1989:H2. This is in sharp contrast to the results based on the log price-to-rent ratio, which identifies as many as nine speculative markets. Second, for the period running from 1994:H1 to 2000:H2, while tests based on the log price-to-rent ratios suggest the existence of speculation in many of the 23 MSA housing markets (ranges from 4 to 14), results from the bubble component indicate the opposite - no speculative bubble behaviour is detected in any of the 23 housing markets for this sample period. Third, both approaches find evidence of speculation in the late 1980s, early-to-mid 2000s before the subprime mortgage crisis, and the early 2010s after the crisis, although in terms of markets involved, the number suggested by the bubble component is far less than that from the log price-to-rent ratio. Overall, Figure 7 clearly stresses the importance of controlling for impact of macroeconomic factors in bubble detection, especially avoiding false positive conclusions.

Lastly, based on the bubble component, there are fewer speculative markets in the late 1980s than the episodes before and after the subprime mortgage crisis. Specifically, the maximum number of speculative markets in those three episodes are respectively two, ten and five. The episode before the subprime mortgage crisis has the largest scale and longest duration.

\subsection{Markets with no or only a short-period of speculation}

While the log price-to-rent ratio based PSY procedure suggests that all markets have speculative bubble behaviour at various periods, the procedure of controlling for macroeconomic factors indicates no speculation for eight of the MSA housing markets across the whole sample period. This includes two Mid West MSAs (Milwaukee and St. Louis), one Northeast (Pittsburgh), two South (Houston and Miami), and three West MSAs (Denver, Honolulu, and Portland). This result suggests that the explosive episodes in the log price-to-rent ratio for those metropolitan areas are due to changes in the macroeconomic conditions rather than speculative bubble behaviour. 
Table 1 displays the bubble periods identified by the PSY procedure using the price-to-rent ratios for those MSAs (top panel). Taking Honolulu, the most expensive MSA as an example, without taking the real interest rate and macroeconomic variables into consideration, three episodes of explosiveness are identified: one in the late 1980s, one before the subprime mortgage crisis (2003-2007), and one in 1997. The dynamics of the market fundamental variables of Honolulu are described in Figure 8: real rent growth rate and real interest rate in panel (a), and real per capita income growth rate, employment growth rate and population growth rate in panel (b). We observe a dramatic increase in the population growth rate in the late 1980s and a similar but smaller magnitude rise in the series in 2004-2006. Both episodes are accompanied by a high level of real per capita income growth and employment growth rates. In addition, there is one small spike in 1989, and two relatively bigger spikes in the real rent growth rates in 2006 and 2009. The testing results reveal that it is important to take those changes into consideration when detecting speculative bubble behaviours in the housing market.

Furthermore, there are four MSAs where only one observation is found to be explosive in the whole sample period based on the proposed procedure (Table 1 bottom panel). They are Cincinnati, Kansas City, Dallas, and Seattle. The PSY procedure finds an explosive dynamic in the bubble component in 2006:H1 in both Kansas City and Seattle. Speculative behaviour is found in 2010:H2 for Cincinnati and in 1993:H2 for Dallas. The periods identified by the PSY procedure based on the log price-to-rent ratio are much more, suggesting that there were speculations in the Seattle housing market in the late 1980s, in all four markets before the subprime mortgage crisis (with various origination and termination dates), and in two markets (Cincinnati and Kansas City) after the subprime mortgage crisis. See Table 1 for the exact periods of identification.

\subsection{Markets with longer-periods of speculation}

The testing results from the other eleven MSAs (Chicago, Cleveland, Detroit, Minneapolis, Boston, New York, Philadelphia, Atlanta, Los Angeles, San Diego, and San Francisco) are listed in Table 2. We look first at results based on the bubble components. Four MSAs are found to have speculative bubble behaviour in the late 1980s, detected firstly in Boston and New York in 1987:H1, San Francisco in 1988:H2 and Los Angeles in 1989:H2.

Interestingly, this finding corresponds nicely with the results of Himmelberg et al. (2005), where 
a completely different approach was taken for bubbles detection. Himmelberg et al. (2005) calculates the true one-year cost of owning a house (imputed rent) and compares it to rental costs or income levels for the period from 1980 to 2004. This user cost calculation takes into consideration the impact of the real interest rate, mortgagee and property tax payments, maintainable costs, expected capital gain, and expected risk premium. If the true cost of owning is far above its competitors, it implies that homeowners have unreasonably high expectations about future capital gains leading them to pay too high a price for a house and hence a house price bubble occurs.

Apart from Detroit and Atlanta, all other MSAs listed in this table are found to be speculative before the subprime mortgage crisis. The earliest speculation behaviour was detected in the Boston housing market in 2001:H1, followed by San Francisco, Cleveland and New York in 2002 and Los Angeles, Chicago, Philadelphia, San Diego, and Minneapolis in 2004:H2. In contrast, the method of Himmelberg et al. (2005) reveals little evidence of bubbles as at the end of 2004.

Surprisingly, the procedure also finds the existence of bubbles in five MSAs for the period after the subprime mortgage crisis, namely Chicago, Cleveland, Detroit, Minneapolis, and Atlanta. Such an episode is first found in Detroit in 2008:H2, then in Cleveland, Minneapolis and Atlanta in 2010, and in Chicago in 2011:H2 (a single explosive observation).

Comparing with results based on the log price-to-rent ratio, there are significant declines in the numbers of bubbles identified for each of the MSAs and the estimated bubble duration becomes shorter after controlling for changes in the macroeconomic conditions. For example, the identified number of bubble episodes in Philadelphia reduces from three to one. For the remaining one bubble episode, the estimated termination date from both approaches is the same (2008:H1), while the estimated starting date from the one with the bubble component is two and a half years later than that from the log price-to-rent ratio (2004:H2 versus 202:H1). On the other hand, for Minneapolis, besides the subprime episode, the procedure detects one more bubble episode in 2010:H2-2012:H1 after taking changes in the macroeconomic conditions into account.

\section{Conclusion}

We have proposed a new method for detecting speculative bubbles in housing markets. Unlike the existing bubble detection methods, the new method explores information beyond the housing market and takes the aggregate economic conditions into consideration. Macroeconomic factors 
such as real interest rate, real per capita income growth, and employment and population growth are included in the forecasting of future streams of real rent growth and real interest rates, which are subsequently used in the calculations of housing market fundamentals. The bubble detection method of Phillips, Shi and Yu (2015a,b) is then applied to the residual component. The new method, which provides a better control for housing market fundamentals, is expected to significantly reduce the chance of false identification.

We have studied the 23 US metropolitan statistical areas and the national housing markets in detail for the period from 1978 to 2012. Based on the log price-to-rent ratio, the PSY procedure finds explosive dynamics in every MSA housing market at various periods. By contrast, after controlling for changes in the macroeconomic conditions using the new procedure, twelve MSA housing markets are found with either none or only a single observation of speculation within the whole sample period. For the remaining eleven MSAs, four are found to have speculative bubble behaviour in the late 1980s (Boston, New York, San Francisco and Los Angeles), nine (Boston, San Francisco, Cleveland, New York, Los Angeles, Chicago, Philadelphia, San Diego, and Minneapolis) for the period between 2001 to 2006, and five MSAs (Chicago, Cleveland, Detroit, Minneapolis, and Atlanta) after the subprime mortgage crisis. Both of the first two episodes were led by speculative behaviours in the Boston housing market and spread to other markets subsequently. The early-tomid 2000s' bubble episode is the most severe one involving nine metropolitan statistical areas.

\section{References}

Bernanke, B. S. (2010). Monetary policy and the housing bubble. In Speech at the Annual Meeting of the American Economic Association, Atlanta, Georgia, Volume 3.

Campbell, S. D., M. A. Davis, J. Gallin, and R. F. Martin (2009). What moves housing markets: A variance decomposition of the rent-price ratio. Journal of Urban Economics 66(2), 90-102.

Case, K. E. (1992). The real estate cycle and the economy: Consequences of the Massachusetts boom of 1984-87. Urban Studies 29(2), 171-183.

Case, K. E., E. L. Glaeser, and J. A. Parker (2000). Real estate and the macroeconomy. Brookings Papers on Economic Activity 2000(2), 119-162. 
Case, K. E., J. M. Quigley, and R. J. Shiller (2005). Comparing wealth effects: The stock market versus the housing market. Advances in macroeconomics 5(1), 1534-6013.

Caspi, I. (2015). Testing for a housing bubble at the national and regional level: The case of Israel. Empirical Economics, forthcoming.

Davis, M. A., A. Lehnert, and R. F. Martin (2008). The rent-price ratio for the aggregate stock of owner-occupied housing. Review of Income and Wealth 54(2), 279-284.

Diba, B. T. and H. I. Grossman (1988). Explosive rational bubbles in stock prices? The American Economic Review 78(3), 520-530.

Engsted, T., S. J. Hviid, and T. Q. Pedersenx (2014). Explosive bubbles in house prices? Evidence from the OECD countries. Working paper.

Greenaway-McGrevy, R. and P. C. Phillips (2015). Hot property in New Zealand: Empirical evidence of housing bubbles in the metropolitan centres. New Zealand Economic Papers 08/2015.

Hall, S. G., Z. Psaradakis, and M. Sola (1999). Detecting periodically collapsing bubbles: A Markov-switching unit root test. Journal of Applied Econometrics 14(2), 143-154.

Himmelberg, C., C. Mayer, and T. Sinai (2005). Assessing high house prices: Bubbles, fundamentals and misperceptions. The Journal of Economic Perspectives 19(4), 67-92.

Homm, U. and J. Breitung (2012). Testing for speculative bubbles in stock markets: a comparison of alternative methods. Journal of Financial Econometrics 10(1), 198-231.

Kishor, N. K. and J. Morley (2015). What factors drive the price-rent ratio for the housing market? A modified present-value analysis. Journal of Economic Dynamics and Control 58(3), 235-249.

Kivedal, B. K. (2013). Testing for rational bubbles in the housing market. Journal of Macroeconomics 38(Part B), 369-381.

McCarthy, J. and R. W. Peach (2004). Are home prices the next bubble? Economic Policy Review 10(3). 
Pavlidis, E., A. Yusupova, I. Paya, D. A. Peel, E. Martinez-Garcia, A. Mack, and V. Grossman (2015). Episodes of exuberance in housing markets: in search of the smoking gun. Journal of Real Estate Finance and Economics.

Phillips, P. C., S. Shi, and J. Yu (2014). Specification sensitivity in right-tailed unit root testing for explosive behaviour. Oxford Bulletin of Economics and Statistics 76(3), 315-333.

Phillips, P. C., S. Shi, and J. Yu (2015a). Testing for multiple bubbles: Historical episodes of exuberance and collapse in the S\&P 500. International Economic Review 56(4), 1043-1078.

Phillips, P. C., S. Shi, and J. Yu (2015b). Testing for multiple bubbles: Limit theory of real time detectors. International Economic Review 56(4), 1079-1134.

Phillips, P. C., Y. Wu, and J. Yu (2011). Explosive behavior in the 1990s NASDAQ: When did exuberance escalate asset values? International Economic Review 52(1), 201-226.

Shi, S. (2013). Specification sensitivities in the Markov-switching unit root test for bubbles. Empirical Economics 45(2), 697-713.

Shi, S. and Y. Song (2016). Identifying speculative bubbles using an infinite hidden Markov model. Journal of Financial Econometrics 14(1), 159-184.

Skinner, J. S. (1996). Is housing wealth a sideshow? In Advances in the Economics of Aging. University of Chicago Press.

Sun, X. and K. P. Tsang (2013). Housing markets, regulations and monetary policy. Working papers, Virginia Polytechnic Institute and State University, Department of Economics. 
Figures

Figure 1: The 2000 average price and rent values for US and all MSAs

(a) Housing price

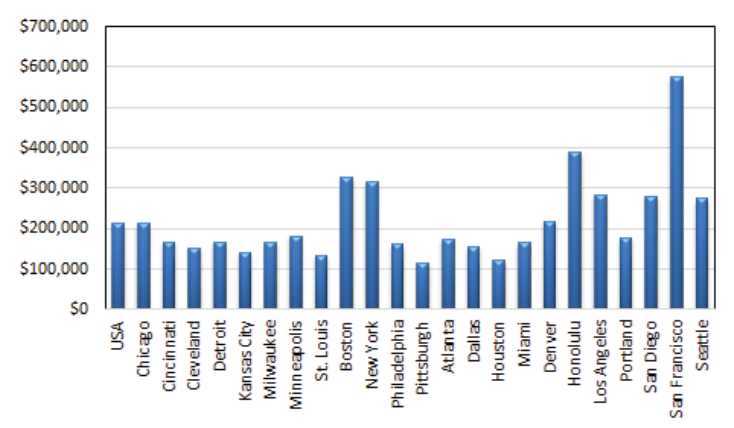

(b) Rent

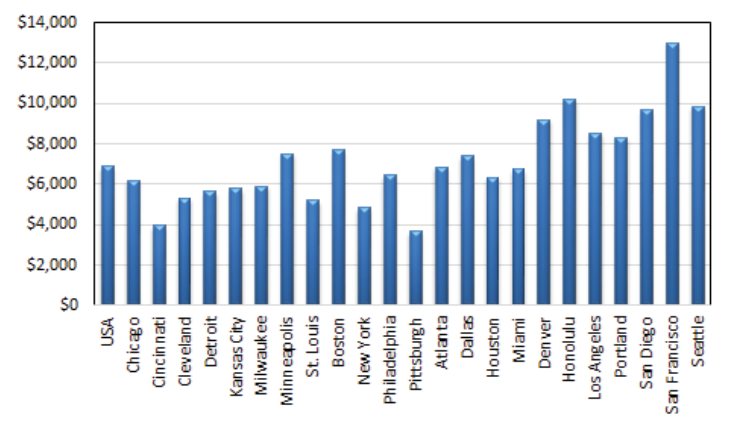


Figure 2: The log price-to-rent ratio of all metropolitan areas.

(a) Mid West

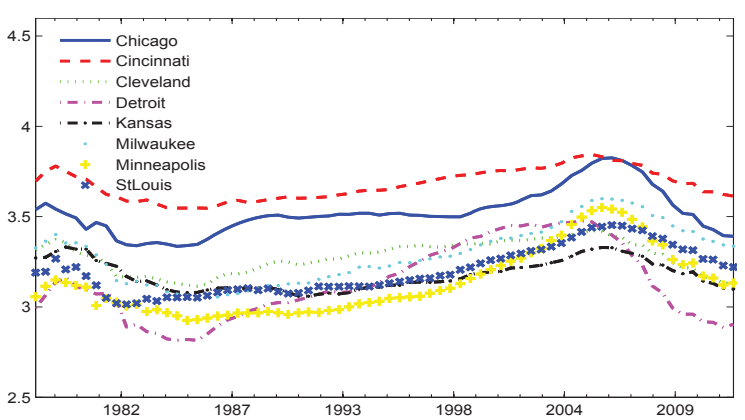

(c) South

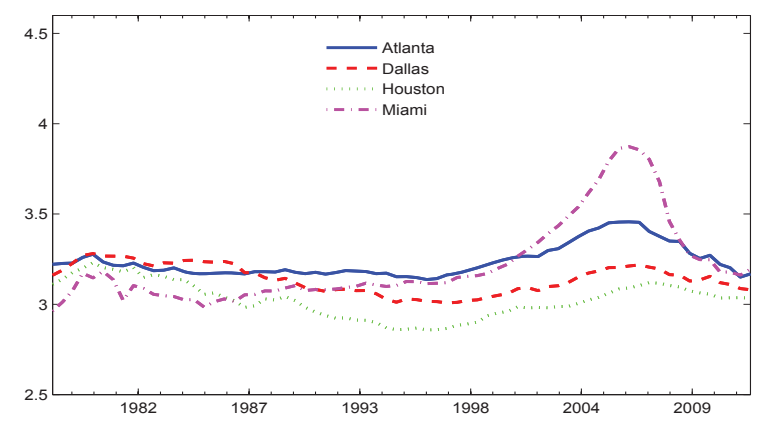

(b) Northeast

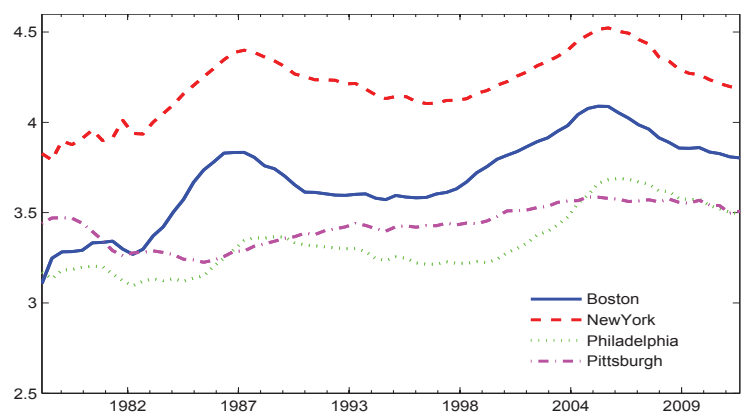

(d) West

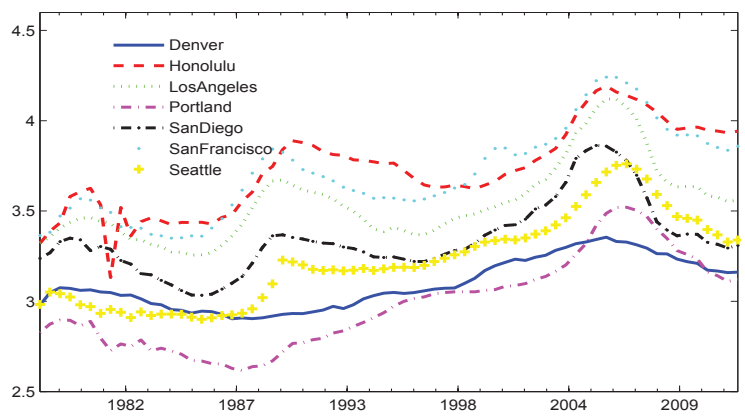


Figure 3: Panel (a) displays the log price-to-rent ratio, annualized real growth rate of rent, and real interest rate for the nation. Panel (b) shows the annualized growth rates of real per capita income, employment and population for the nation.

(a)

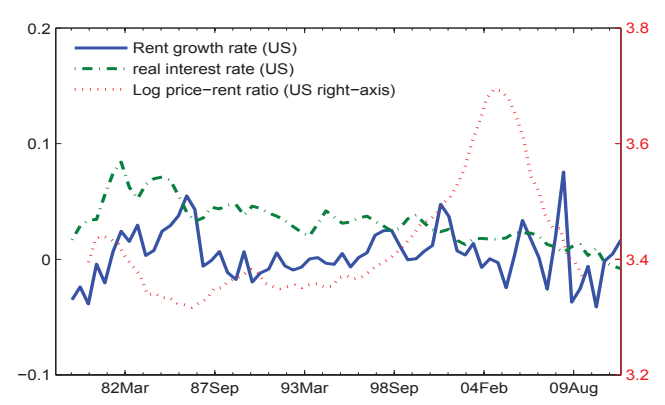

(b)

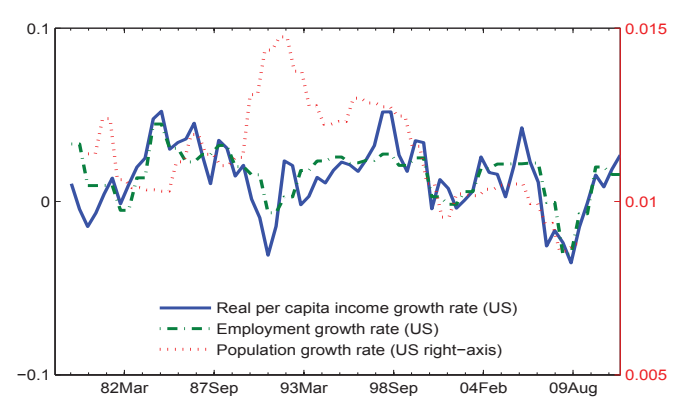


Figure 4: Actual versus fitted series in the US national market

(a) Real interest rate

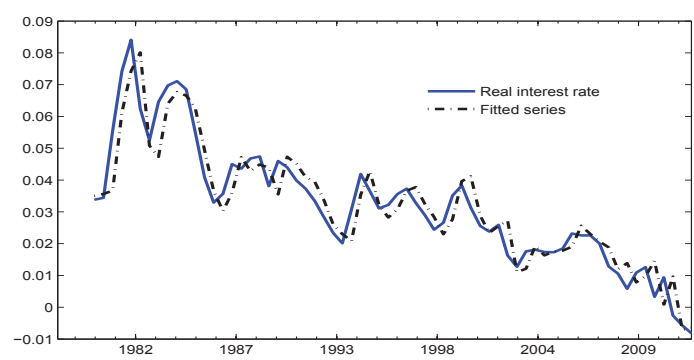

(c) Real per capita GDP growth rate

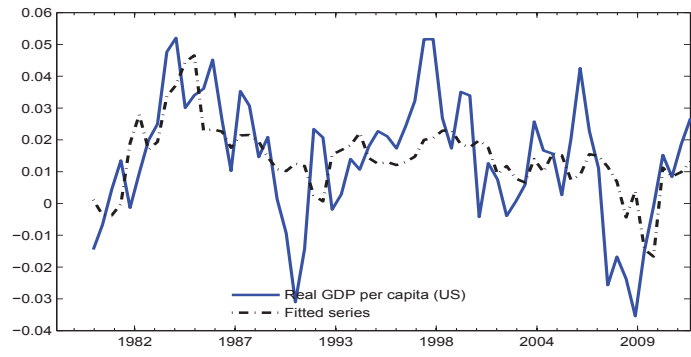

(e) Population growth rate

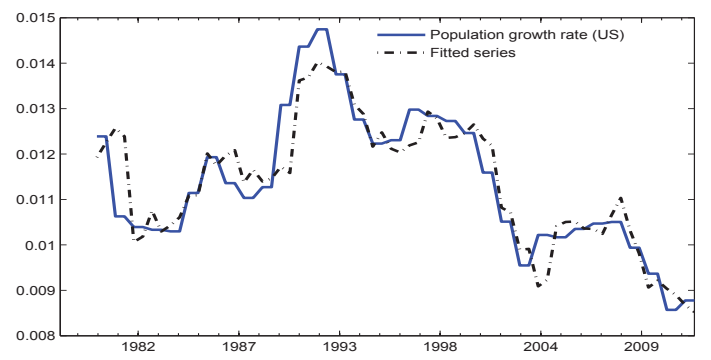

(b) Rent growth rate

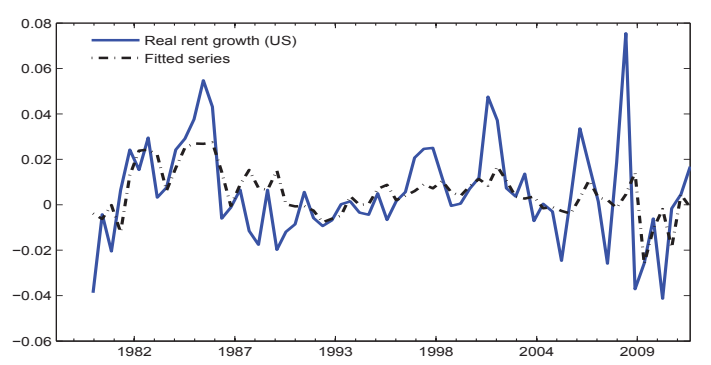

(d) Employment growth rate

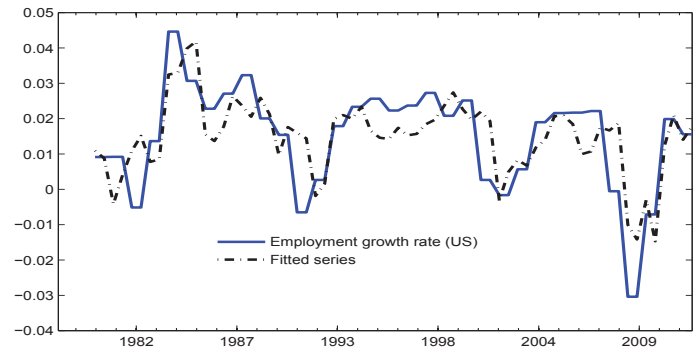

(f) Residual component of the log price-to-rent ratio

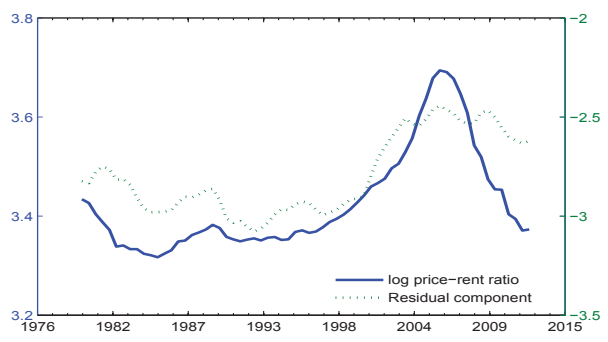


Figure 5: The bubble component of the log price-to-rent ratio for all metropolitan areas.

(a) Mid West

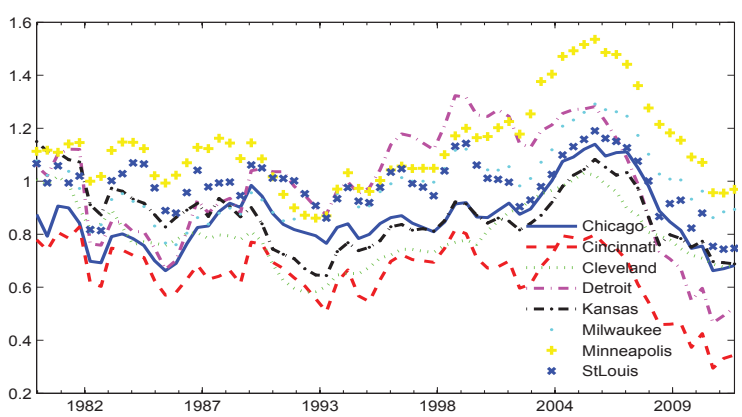

(c) South

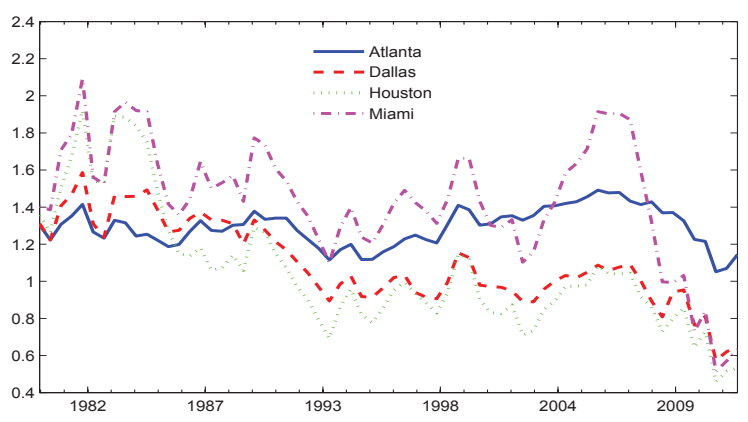

(b) Northeast

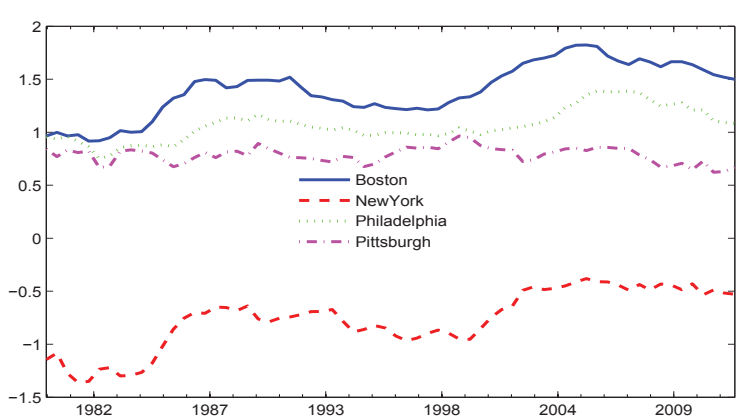

(d) West

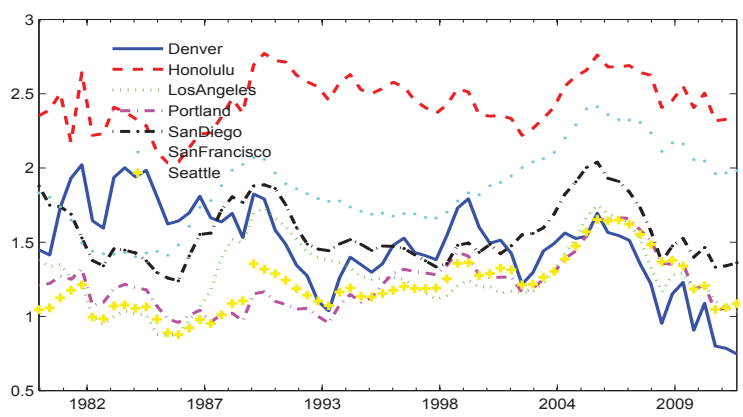


Figure 6: Dating explosive dynamics in the log price-to-rent ratio and the residual component of the national housing market.

(a) $\log$ price-to-rent ratio

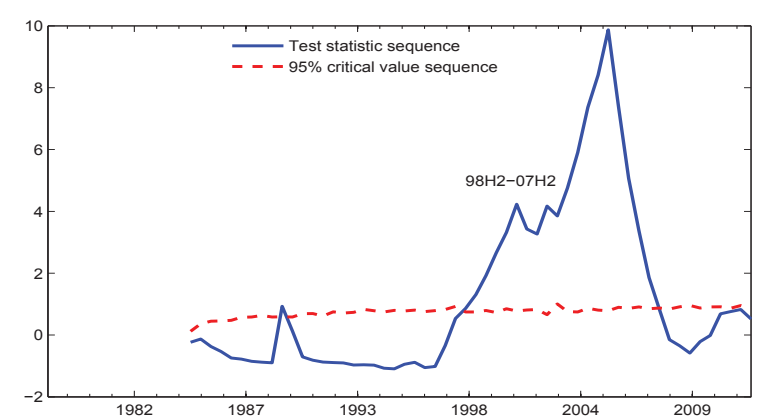

(b) Residual Component

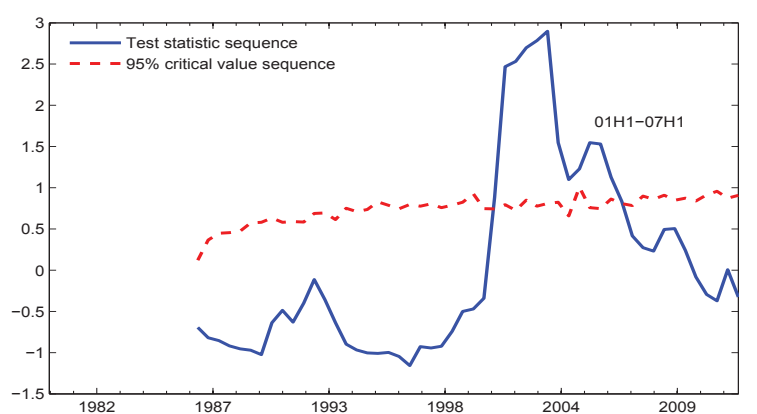


Figure 7: Number of explosive MSA housing markets

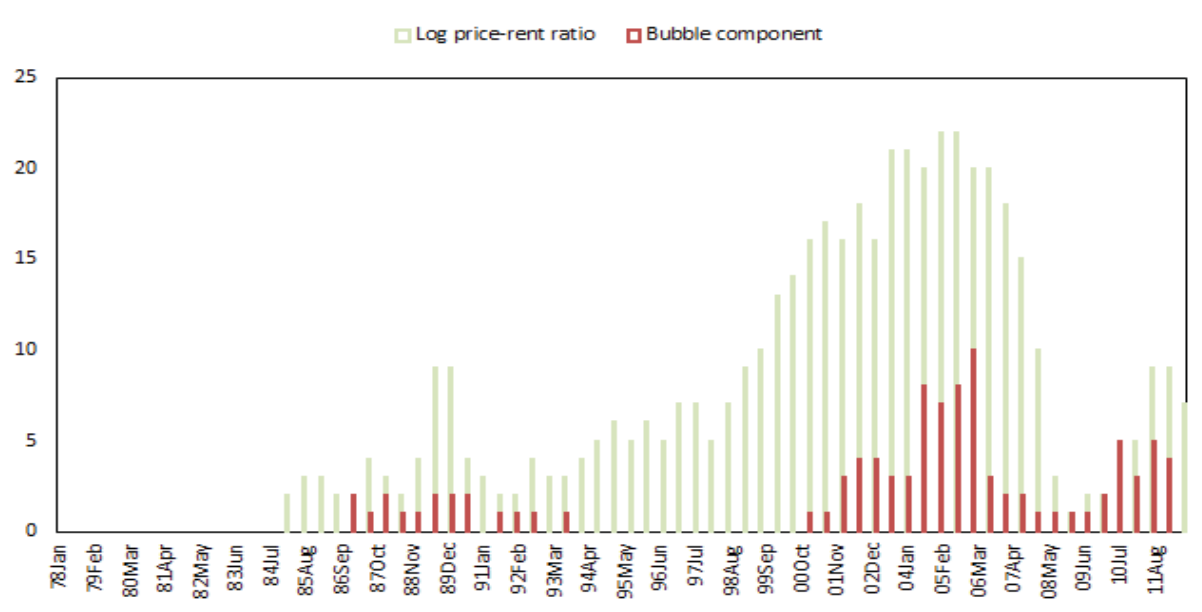


Figure 8: Panel (a) displays the real rent growth rate of Honolulu and the real interest rate. Panel (b) shows the real per capita income growth rate, employment growth rate and population growth rate of Honolulu.

(a)

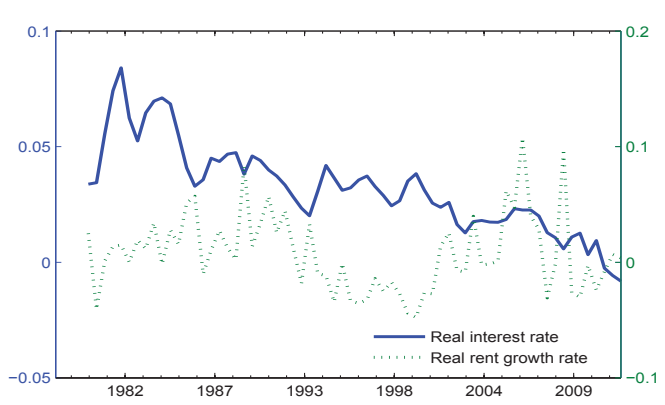

(b)

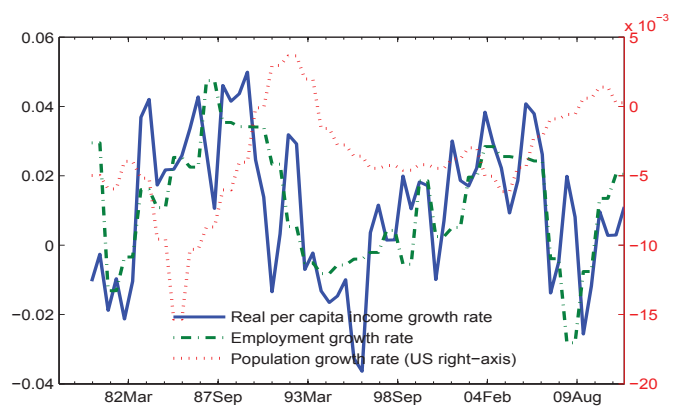




\section{Tables}

Table 1: The identified bubble periods using the PSY procedure based on the log price-to-rent ratio for Milwaukee, St. Louis, Pittsburgh, Houston, Miami, Denver, Honolulu, and Portland (top panel) and for Cincinnati, Kansas City, Dallas, and Seattle (bottom panel).

\begin{tabular}{lll}
\hline & Log price-to-rent ratio & Bubble component \\
Milwaukee & 1992H1-2008H1, 2011H2-2012H2 & \\
St. Louis & $1999 \mathrm{H} 1-2008 \mathrm{H} 1,2011 \mathrm{H} 2-2012 \mathrm{H} 2$ & \\
Pittsburgh & $1990 \mathrm{H} 1-1991 \mathrm{H} 1,1992 \mathrm{H} 1-1993 \mathrm{H} 2,2001 \mathrm{H} 1,2002 \mathrm{H} 2,2003 \mathrm{H} 2-2005 \mathrm{H} 2$ & \\
Houston & $1987 \mathrm{H} 2,2001 \mathrm{H} 1,2005 \mathrm{H} 1-2008 \mathrm{H} 2$ & \\
Miami & $2000 \mathrm{H} 1-2008 \mathrm{H} 1$ & \\
Denver & $1985 \mathrm{H} 2,1987 \mathrm{H} 2,1994 \mathrm{H} 1-1995 \mathrm{H} 2,1997 \mathrm{H} 1-\mathrm{H} 2,1998 \mathrm{H} 2-2008 \mathrm{H} 1,2011 \mathrm{H} 1-$ & \\
& $2012 \mathrm{H} 1$ & $2010 \mathrm{H} 2$ \\
Honolulu & $1989 \mathrm{H} 2-1991 \mathrm{H} 2,1997 \mathrm{H} 1-\mathrm{H} 2,2003 \mathrm{H} 2-2007 \mathrm{H} 1$ & $2006 \mathrm{H} 1$ \\
Portland & $1992 \mathrm{H} 2-2008 \mathrm{H} 2$ & $1993 \mathrm{H} 2$ \\
\hline Cincinnati & $1996 \mathrm{H} 1-2006 \mathrm{H} 2,2011 \mathrm{H} 1-2012 \mathrm{H} 2$ & $2006 \mathrm{H} 1$ \\
Kansas City & $1985 \mathrm{H} 1,1999 \mathrm{H} 2-2007 \mathrm{H} 2,2011 \mathrm{H} 2-2012 \mathrm{H} 2$ & \\
Dallas & $1990 \mathrm{H} 2-1991 \mathrm{H} 2,1994 \mathrm{H} 2-1995 \mathrm{H} 1,2001 \mathrm{H} 2,2003 \mathrm{H} 2-2007 \mathrm{H} 1$ & \\
Seattle & $1989 \mathrm{H} 2-1990 \mathrm{H} 2,1998 \mathrm{H} 2-2008 \mathrm{H} 1$ & \\
\hline
\end{tabular}


Table 2: The identified bubble periods for the nation and all other MSAs.

\begin{tabular}{lll}
\hline & Log price-to-rent ratio & Bubble component \\
US & 1989H2, 1998H2-2007H2 & 2001H1-2007H1 \\
Chicago & $1989 H 1-1990 H 1,2001 \mathrm{H} 2-2007 \mathrm{H} 2,2011 \mathrm{H} 1-2012 \mathrm{H} 2$ & $2004 \mathrm{H} 2,2005 \mathrm{H} 2-2006 \mathrm{H} 1,2011 \mathrm{H} 2$ \\
Cleveland & $1989 \mathrm{H} 2-1990 \mathrm{H} 1,1996 \mathrm{H} 1,2005 \mathrm{H} 2,2009 \mathrm{H} 2-2012 \mathrm{H} 2$ & $1991 \mathrm{H} 2-1992 \mathrm{H} 2,2002 \mathrm{H} 1-2006 \mathrm{H} 1,2010 \mathrm{H} 1-2012 \mathrm{H} 1$ \\
Detroit & $1989 \mathrm{H} 2-1990 \mathrm{H} 1, \quad 1992 \mathrm{H} 2, \quad 1995 \mathrm{H} 2-2002 \mathrm{H} 2, \quad 2003 \mathrm{H} 2-$ & $2008 \mathrm{H} 2-2012 \mathrm{H} 1$ \\
& $2004 \mathrm{H} 1,2005 \mathrm{H} 1,2007 \mathrm{H} 2-2012 \mathrm{H} 2$ & \\
Minneapolis & $1994 \mathrm{H} 1-2008 \mathrm{H} 1$ & $2004 \mathrm{H} 2-2006 \mathrm{H} 1,2010 \mathrm{H} 2-2012 \mathrm{H} 1$ \\
Boston & $1985 \mathrm{H} 2-1988 \mathrm{H} 1,1999 \mathrm{H} 1-2006 \mathrm{H} 2$ & $1987 \mathrm{H} 1-1988 \mathrm{H} 1,2001 \mathrm{H} 1-2006 \mathrm{H} 1$ \\
New York & $1986 \mathrm{H} 1-1988 \mathrm{H} 1,2001 \mathrm{H} 2-2007 \mathrm{H} 1,2011 \mathrm{H} 2$ & $1987 \mathrm{H} 1,1988 \mathrm{H} 1,2002 \mathrm{H} 2-2003 \mathrm{H} 1$ \\
Philadelphia & $1988 \mathrm{H} 1-1989 \mathrm{H} 2,1995 \mathrm{H} 1,2002 \mathrm{H} 1-2008 \mathrm{H} 1$ & $2004 \mathrm{H} 2-2008 \mathrm{H} 1$ \\
Atlanta & $2000 \mathrm{H} 1-2001 \mathrm{H} 2,2002 \mathrm{H} 2-2007 \mathrm{H} 2,2012 \mathrm{H} 1$ & $2010 \mathrm{H} 2,2011 \mathrm{H} 2-2012 \mathrm{H} 1$ \\
Los Angeles & $1989 \mathrm{H} 1-1990 \mathrm{H} 1,2001 \mathrm{H} 2-2007 \mathrm{H} 2$ & $1989 \mathrm{H} 2-1990 \mathrm{H} 2,2004 \mathrm{H} 2-2006 \mathrm{H} 2$ \\
San Diego & $1985 \mathrm{H} 1-1986 \mathrm{H} 1,1989 \mathrm{H} 2-1990 \mathrm{H} 1,2000 \mathrm{H} 2-2007 \mathrm{H} 1$ & $2004 \mathrm{H} 2-2006 \mathrm{H} 1$ \\
San Francisco & $1988 \mathrm{H} 2-1990 \mathrm{H} 1,2000 \mathrm{H} 1-2001 \mathrm{H} 1,2003 \mathrm{H} 2-2007 \mathrm{H} 2$ & $1988 \mathrm{H} 2-1990 \mathrm{H} 2,2002 \mathrm{H} 1-2007 \mathrm{H} 2$ \\
\hline
\end{tabular}

